\title{
Acoustical Benefits of Plenum Window as Facade Device - A Parametric Study
}

\author{
Yean Ghing Tong ${ }^{1, *}$, and Shiu-keung Tang ${ }^{2}$ \\ ${ }^{1}$ Jamilus Research Centre, Universiti Tun Hussein Onn Malaysia, 86400 Parit Raja, Johor, Malaysia \\ ${ }^{2}$ Department of Building Services Engineering, Hong Kong Polytechnic University, Hong Kong, \\ China
}

\begin{abstract}
Rapid population growth and economic development have led to serious noise pollution in densely populated cities. As the noise level keeps on increasing, opening windows for natural ventilation has become nearly not possible, especially in urbanized residential areas. Plenum window is the modification of a partially opened double glazing window system to the staggered inlet and outlet window openings which can provide better sound protection to the building and at the same time can allow certain degree of natural ventilation across it. A series of full-scale laboratory measurements were carried out in order find out the relationship between the important parameters and the acoustical performance of plenum window. From the measurement results, plenum window can attenuated at least $10 \mathrm{dBA}$ traffic noise without treatment inside the window system. It is found that window opening sizes and overlapping width have significant effects on the acoustical protection of plenum window.
\end{abstract}

\section{Introduction}

Traffic noise is the major noise pollutant that has affected surrounding populations in densely populated cities. The situation becomes severe in the cities where large numbers of residential dwellings are required to build alongside the main traffic networks to satisfy the housing demands of the communities. When buildings are situated close to traffic roads, environment noise from transportation system becomes source of nuisance in the city. Many surveys were carried out over the century to evaluate the effects of traffic noise exposure to the nearby residents. This environment noise is found to be the most critical effects on human sleep disturbances in several studies [1-4] and could lead to health problems [5].

Roadside barriers are the common structures used in urban areas to reduce human noise exposure due to the noisy road networks in the residential areas [6]. Many studies of roadside barrier including experimental and theoretical have been carried out over the past few decades. Efforts have been made in changing geometries and materials of the barriers in order to improve the performance of barriers [7-9]. However, this measure is not cost-

* Corresponding author: ygtong@uthm.edu.my 
effective and there are some cases where this massive structure cannot be built due to site constraints.

An alternative noise mitigation form is vital to deal with this serious problem. Treatment on the devices that attached on façade could be better solutions to deals with noise from transportation system because traffic noise mainly propagates from outdoor into the indoor environment through building facades. Besides the external walls, large portions of building façades are covered by windows which are designed to admit natural daylight and ventilation into the buildings. This makes window become a weak point of the facade because window constitutes the primary path of traffic noise enters into built environment. Natural ventilation and noise control are two conflicting issues. When natural ventilation is provided across the facade, windows will become the main noise transmission path for external noise ingress. As a results, residents living in the city with high traffic noise levels prefer to close all the windows and use air conditioning system. The use of mechanical ventilation increases electricity demand, energy consumption, environmental problems and against the principle of sustainability.

Recently, the concept of plenum chamber in duct silencing [10] has been proposed to be used in the window system [11]. The inlet and outlet openings of the proposed window system were designed in the zigzag configuration to block direct sound path from the outdoor to the indoor environment. This staggered inlet and outlet opening window system, referred as plenum window hereafter, has been attracted many researchers as it can provide high sound insulation while allowing natural ventilation across it. Plenum window proved to be effective on providing acoustical protection to the residential buildings compared to the conventional window system $[12,13]$. In this paper, full scale laboratory measurements were carried out to investigate the effects of various plenum window configuration parameters to the acoustical performance of this facade device.

\section{Measurement setup}

\subsection{Test chamber}

All the measurements were carried out inside acoustic testing chamber of the Department of Building Services Engineering, The Hong Kong Polytechnic University. The test chambers were two coupled but isolated chambers originally used for the ISO 10140-2 tests [14] for sound transmission loss of building materials. The bigger chamber, usually used as source room, had a volume of about $240 \mathrm{~m}^{3}$ and a height of $5 \mathrm{~m}$, while the smaller one, usually used as the receiver room, had a volume of $\sim 84 \mathrm{~m}^{3}$. The source room was converted into a semi-echoic chamber by putting up 2-inch thick fibreglass curtains at about $1 \mathrm{~m}$ away from all walls and ceiling. This setup was made similar to the Kang's study [15].

\subsection{Sound source}

Traffic noise is regarded as a line source [16]. In this study, a 5m long line source consisted of 25 six-inch aperture loudspeakers was adopted to simulate road traffic noise. A constant magnitude of white noise signals were supplied by Brüel \& Kjær 1405 Noise Generator, which was connected to a power amplifier to drive the loudspeakers. The loudspeaker array was placed on floor and located at $5 \mathrm{~m}$ horizontally away from the tested window. 


\subsection{Tested window configurations}

Two different window systems, conventional casement window and plenum window were tested in the present study. The plenum window is composed of two layers of window systems where the outer layer is casement window and fixed glazed window while the inner layer is a movable sliding glass pane as shown in Fig. 1. This window design allows either direct opening or offset opening configurations by adjusting the position of the inner layer of the sliding glass pane. The window system was remained in the offset opening condition throughout the test. Two different configurations of outer side window, the single-leaf and the double-leaves casement windows were included in this study.

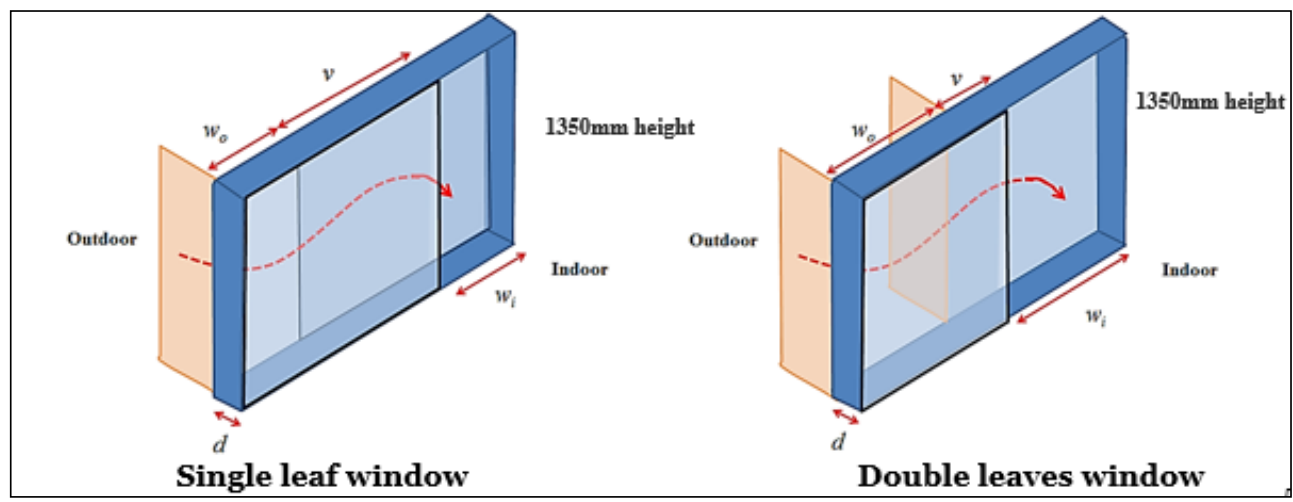

Fig. 1. Plenum window schematics. (left) Single leaf window; (right) Double leaves window

The performance of plenum window under different combinations of inner side window opening size $\left(w_{i}\right)$, outer side window opening size $\left(w_{o}\right)$, gap width $(d)$ and overlapping length $(v)$ with and without lining of sound absorption materials as shown in Table 1 were investigated. Fibreglass was lined inside the plenum cavity (top and both sides) which fitted the gap width $(d)$ of the window system for the cases that plenum window were treated by sound absorption materials. From Table 1, eight different configurations of plenum windows were to compare with a single set of conventional casement window. The total length of the windows depended on the window opening sizes and overlapping length. The heights of all tested windows were $1350 \mathrm{~mm}$. All windows glass panes were made of $6 \mathrm{~mm}$ thick single glazing with aluminium frames.

\subsection{Measurement procedure}

A total of nine Brüel \& Kjær Type 4935 microphones were used in the receiver room used to capture the transmitted sound level. These microphones were spanned over the whole volume of the receiver room (at least $1 \mathrm{~m}$ away from walls) as shown in Fig. 2. On the other hand, the number of microphones used at the source room was depended on the size of the tested window start from three, nine and twelve microphones as shown in Fig. 3. The microphones at the source room side were placed at $1 \mathrm{~m}$ horizontally from the tested windows to estimate the average sound pressure level falling onto the tested specimens. All microphone signals were recorded simultaneously by Brüel \& Kjær 3506D PULSE system. Three measurements were recorded for each setting which each measurement lasted for 30 seconds. The results presented later in this paper are the corresponding average values.

Since the objective of the present study is to estimate the acoustical protection of the plenum window in the presence of traffic noise, the normalized traffic noise spectrum 
depicted in the standard EN 1793-3 [17] was adopted. This normalized traffic noise spectrum was used in the estimation of the acoustical benefit of plenum window in term of a single rating.

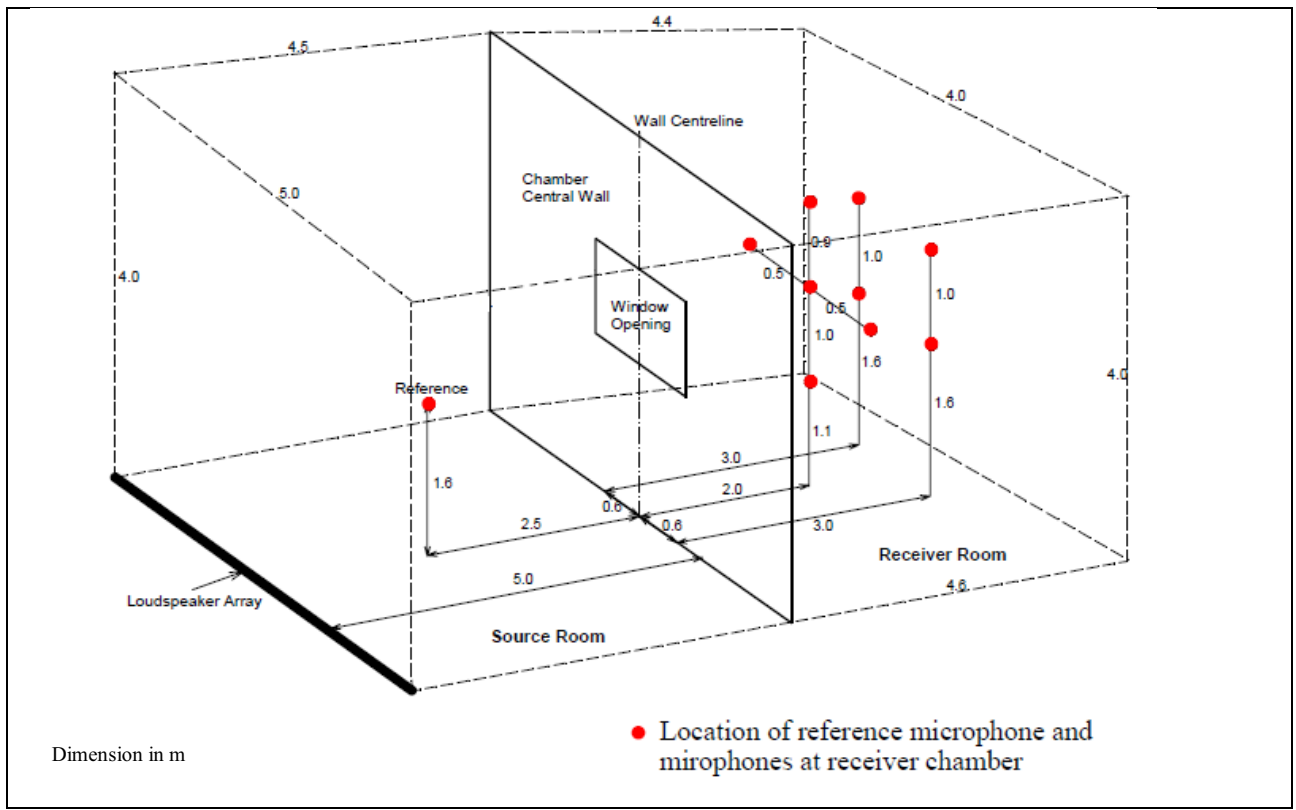

Fig. 2. Location of reference microphones and microphones at receiver room.

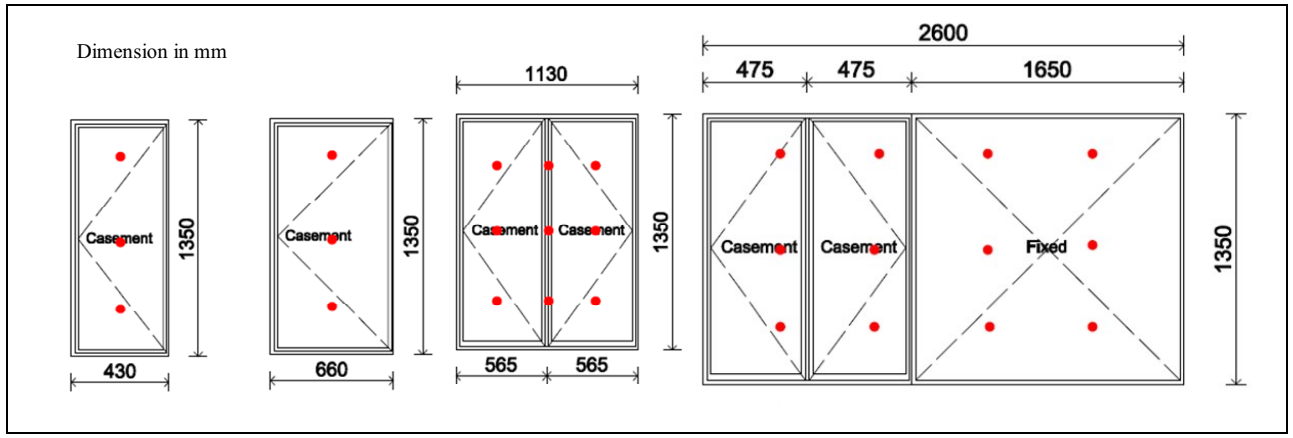

Fig. 3. Different location of microphone for different size of window at the source rooms.

Transmission loss $(T L)$ was obtained from the differences of band noise levels between the source room and receiver room. This estimation evaluated the acoustical benefits offered by plenum window itself without make the comparison with the conventional casement window. The single rating TL can be expressed as follow.

$$
\begin{gathered}
\mathrm{T}_{\mathrm{i}}=S P L_{i, \text { source }}-S P L_{\mathrm{i}, \text { receiver }} \\
T L=10 \log _{10}\left(\frac{\sum_{\mathrm{i}=1}^{18} 10^{0.1\left(\mathrm{~N}_{\mathrm{i}}-\mathrm{T}_{\mathrm{i}}\right)}}{\sum_{\mathrm{i}=1}^{18} 10^{0.1 \mathrm{~T}_{\mathrm{i}}}}\right)
\end{gathered}
$$


where $i$ represents the $i$ th one-third octave band data, from $100 \mathrm{~Hz}$ to $5 \mathrm{kHz}, S P L_{i, \text { source }}$ the average band level obtain in the source room, $S P L_{i, \text { receiver }}$ the average band level obtain in the receiver chamber, $N_{i}$ the normalized noise band level.

Another acoustical benefits that estimated in the present study is insertion loss $\left(I L_{A}\right)$ which is obtained from the differences of band noise levels inside the receiver room after replacing a conventional casement window by a plenum window. A single rating of insertion loss $\left(I L_{A}\right)$ of plenum window when exposed to traffic noise can be defined as followed expression.

$$
\begin{gathered}
\mathrm{R}_{\mathrm{i}}=S P L_{\mathrm{i}, \text { conventional }}-S P L_{\mathrm{i}, \text { Plenum }} \\
I L_{A}=10 \log _{10}\left(\frac{\sum_{\mathrm{i}=1}^{18} 10^{0.1\left(\mathrm{~N}_{\mathrm{i}}-\mathrm{R}_{\mathrm{i}}\right)}}{\sum_{\mathrm{i}=1}^{18} 10^{0.1 \mathrm{~N}_{\mathrm{i}}}}\right)
\end{gathered}
$$

\section{Measurement results}

\begin{tabular}{|c|c|c|c|c|c|c|c|}
\hline \multirow[b]{2}{*}{ Scenario } & \multirow{2}{*}{$\begin{array}{l}\text { Casement } \\
\text { window } \\
\text { width }\end{array}$} & \multicolumn{4}{|c|}{ Plenum window } & \multirow[b]{2}{*}{$\begin{array}{c}T L \\
(\mathrm{dBA})\end{array}$} & \multirow[b]{2}{*}{$\begin{array}{c}I L_{A} \\
(\mathrm{dBA})\end{array}$} \\
\hline & & $\begin{array}{l}w_{o} \\
w_{i}\end{array}$ & $v$ & $d$ & Fibreglass & & \\
\hline L1 & \multirow{8}{*}{$\begin{array}{c}430 \\
\text { (Single } \\
\text { leaf) }\end{array}$} & \multirow{8}{*}{320} & \multirow{4}{*}{100} & \multirow{2}{*}{145} & Yes & 17.2 & 9.8 \\
\hline L2 & & & & & No & 15.6 & 7.5 \\
\hline L3 & & & & \multirow{2}{*}{205} & Yes & 18.2 & 13.0 \\
\hline L4 & & & & & No & 16.7 & 10.3 \\
\hline L5 & & & \multirow{4}{*}{700} & \multirow{2}{*}{145} & Yes & 19.0 & 14.2 \\
\hline L6 & & & & & No & 16.9 & 10.8 \\
\hline L7 & & & & \multirow{2}{*}{205} & Yes & 18.9 & 13.2 \\
\hline L8 & & & & & No & 16.7 & 9.6 \\
\hline L9 & \multirow{8}{*}{$\begin{array}{c}660 \\
\text { (Single } \\
\text { leaf) }\end{array}$} & \multirow{8}{*}{600} & \multirow{4}{*}{100} & \multirow{2}{*}{145} & Yes & 17.4 & 13.0 \\
\hline L10 & & & & & No & 16.2 & 11.2 \\
\hline L11 & & & & \multirow{2}{*}{205} & Yes & 17.0 & 11.2 \\
\hline L12 & & & & & No & 15.3 & 8.8 \\
\hline L13 & & & \multirow{4}{*}{700} & \multirow{2}{*}{145} & Yes & 10.3 & 14.2 \\
\hline L14 & & & & & No & 16.9 & 11.6 \\
\hline L15 & & & & \multirow{2}{*}{205} & Yes & 18.8 & 13.5 \\
\hline L16 & & & & & No & 16.1 & 9.7 \\
\hline L17 & \multirow{8}{*}{$\begin{array}{l}1130 \\
\text { (Double } \\
\text { leaves) }\end{array}$} & \multirow{8}{*}{950} & \multirow{4}{*}{100} & \multirow{2}{*}{145} & Yes & 15.9 & 13.9 \\
\hline L18 & & & & & No & 14.6 & 11.6 \\
\hline L19 & & & & \multirow{2}{*}{205} & Yes & 15.5 & 11.8 \\
\hline L20 & & & & & No & 13.9 & 9.4 \\
\hline L2 1 & & & \multirow{4}{*}{700} & \multirow{2}{*}{145} & Yes & 17.3 & 15.2 \\
\hline $\mathrm{L} 22$ & & & & & No & 15.8 & 12.7 \\
\hline L23 & & & & \multirow{2}{*}{205} & Yes & 17.2 & 13.8 \\
\hline L24 & & & & & No & 15.1 & 11.2 \\
\hline
\end{tabular}

Table 1. Plenum window tested scenarios and insertion losses 


\subsection{Transmission loss $(T L)$}

The results of laboratory measurements of 24 configurations plenum windows are depicted in Table 1. From the table, it show at least $10 \mathrm{dBA}$ of traffic noise can be attenuated by using plenum window system, without any treatment on it. The maximum sound transmission loss obtained from the study was about $19 \mathrm{dBA}$. As expected, plenum window lined with sound absorption materials provided higher sound insulation to the indoor environment for all studied scenarios. For the same plenum window configuration, treatment on the plenum window system can increased about $2 \mathrm{dBA}$ of $T L$.

In general, $T L$ increased when the overlapping width of the plenum window increased especially for the larger opening sizes. This attenuation probably due to the multiple reflections of transmitted noise inside the plenum cavity before it ingress into indoor environment. For the smaller opening sizes $\left(w_{i}\right.$ or $\left.w_{o}=320 \mathrm{~mm}\right)$, wider the overlapping width of the window only provide acoustic benefits to the plenum window that has smaller gap width $(d=145 \mathrm{~mm})$.

When the opening sizes of the plenum window increased, it is noticed that the TL are slightly decreased. About 1.5 to $2 \mathrm{dBA}$ of reduction of $T L$ when the opening sizes of the plenum window expanded from $320 \mathrm{~mm}$ to $950 \mathrm{~mm}$. The reduction of sound attenuation probably due to the facts that plenum window system received more sound waves propagated into the plenum cavity.

The results from the experiments suggested the acoustical transmission loss is not significantly affected by changing the gap width of the plenum window for all range of studied opening sizes and overlapping width.

\subsection{Insertion losses $\left(I L_{A}\right)$}

From the Table 1, one can observe that, for the same opening size, plenum window with larger overlapping width and smaller air gap width results in higher insertion loss $\left(I L_{A}\right)$. The highest acoustic benefit is obtained when the opening and overlapping width of the window are larger $\left(w_{i} / w_{o}=950 \mathrm{~mm} ; v=700 \mathrm{~mm}\right)$, but smaller air gap width $(145 \mathrm{~mm})$. The maximum $I L_{A}$ achieved is about $15 \mathrm{dBA}$. Similar to $T L$, plenum window with sound absorption material provides better sound insulation compared to the plenum window without any treatment. With fiberglass lined inside the cavity, an average of $2.7 \mathrm{dBA}$ increase in term of $I L_{A}$.

It is noticed that increasing the air gap width of plenum window when other parameters are kept unchanged will decrease the $I L_{A}$ except for the case of small opening ( $w_{i}$ or $w_{o}$ ) and small overlapping $(v)$. The same trend of $I L_{A}$ on the effect of air gap width $(d)$ can be observed for the plenum windows lined with sound absorption material. The reduction of $I L_{A}$ appears to decrease when the overlapping length $(v)$ is increased. This is due to the fact that the mean propagation path for the outdoor noise to travel into the receiver room via plenum cavity become shorter when the overlapping length $(v)$ of plenum window is reduced. For the case with small opening $\left(w_{i}\right.$ or $\left.w_{o}\right)$ and small overlapping $(v)$, the window performance is sensitive to the change of air gap width $(d)$ where about 3 dBA reduction can be noticed when $d$ is reduced by $60 \mathrm{~mm}$.

The total length $(L)$ of the plenum window depends on the opening sizes $(w)$ and overlapping length $(v)$. Fig. 4 shows the effects of $w / L$ ratio on the insertion loss $I L_{A}$. Smaller gap width $(d)$ results in higher $I L_{A}$ compared to the larger $d$ cases except at the $w / L=0.43$. It is noticed that the $I L_{A}$ are slightly increased when the $w / L$ is increased from 0.24 to $\sim 0.32$ and more rapid increment can be observed when the ratio is further increased to 0.37 . However, the $I L_{A}$ decreases quickly when the ratio is further increased to $\sim 0.43$. For the case of $w / L=\sim 0.43$, the window opening sizes and the overlapping length are 
small. Faster increase of insertion losses is observed for $w / L>0.43$ for the smaller gap width $(d)$ while the insertion losses keep droping for the cases of larger $d$. The insertion loss of the larger $d$ then increase after $w / L=\sim 0.46$. An average of $2.5 \mathrm{dBA}$ and $\sim 3 \mathrm{dBA}$ insertion loss can be obtained when sound absorption lined in the plenum window with $d=$ $145 \mathrm{~mm}$ and $205 \mathrm{~mm}$, respectively.

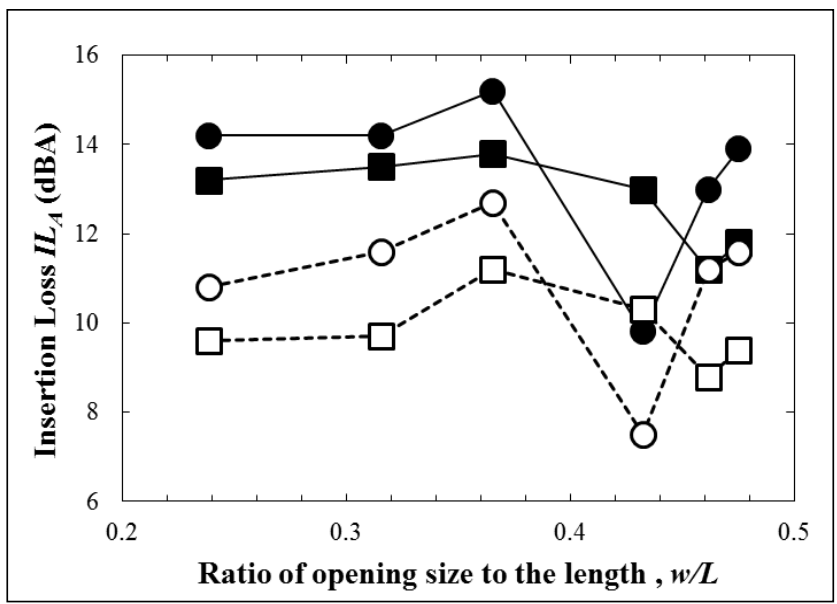

$\bullet: d=145 \mathrm{~mm} ; \boldsymbol{\bullet}: d=205 \mathrm{~mm}$; Closed symbols :

with sound absorption; Opened symbols : without sound absorption.

Fig. 4. Effects of the $\mathrm{w} / \mathrm{L}$ on insertion losses $I L_{A}$

\section{Conclusions}

The investigations of various combinations of full-scale plenum windows were carried out inside the two coupled but isolated chambers. A total of 24 different configurations of plenum windows with various opening sizes $(w)$, gap widths $(d)$ and overlapping lengths $(v)$ with and without sound absorption materials lined inside the plenum cavity were tested. Two acoustical benefits are presented which are transmission loss $T L$ and insertion losses of $I L_{A}$ in the present study. $I L_{A}$ is the difference of noise levels inside the receiver room when the conventional casement window is replaced to a plenum window, while $T L$ is the difference sound levels before entering plenum window and after passing through plenum window.

From the results, it suggested that plenum window is an effective noise screening devices which can be used to attenuate traffic noise. The maximum of $T L$ offers by plenum window is about $19 \mathrm{dBA}$. TL increased with the increasing of overlapping width $(v)$ of plenum window or length of the window. However, increasing of opening sizes of the window system will resulting of reduction of $T L$. The changing of air gap width is found to be insignificantly effects the performance of plenum window in term of $T L$.

Higher insertion loss can be obtained for the window with larger overlapping $(v)$ but smaller gap width $(d)$ when the opening sizes of the plenum are fixed. For these configurations, increasing the opening sizes will enhance the acoustical benefit of the plenum window. The maximum $I L_{A}$ offers by plenum window is about $15 \mathrm{dBA}$. The insertion loss tends to increase with increasing window span, decrease with increasing gap width and decreasing overlapping length in general. 


\section{References}

[1] D.W. Robinson, An outline guide to criteria noise for the limitation of urban, No. 1112. Ministry of Technology, London, United Kingdom, (1970)

[2] A. Skånberg and E. Öhrström, Sleep disturbances from road traffic noise: A comparison between laboratory and field settings, J. Sound Vib., 290(1-2), 3-16 (2006)

[3] E. Öhrström, A. Skånberg, H. Svensson and A. Gidlöf-Gunnarsson, Effects of road traffic noise and the benefit of access to quietness, J. Sound Vib., 295(1-2), 40-59 (2006)

[4] E. Öhrström, E. Hadzibajramovic, M. Holmes and H. Svensson, Effects of road traffic noise on sleep: Studies on children and adults, J. Environ. Psychol., 26(2), 116-126 (2006)

[5] W. Babisch, Road traffic noise and cardiovascular risk, Noise Health, 10(38), 27-33 (2008)

[6] I. Ekici and H. Bougdah, A review of research on environmental noise barriers, Building Acoustics, 10(4), 289-323 (2003)

[7] G.R. Watts, D. H. Crombie and D. C. Hothersall, Acoustic performance of new designs of traffic noise barriers: Full scale tests, J. Sound Vib., 177(3), 289-305 (1994)

[8] M. Auerbach, A. Bockstedteb and O.V Estorff, Numerical and experimental investigations of noise barriers with helmholtz resonators, Proc. of Noise-Con 2010, Maryland, United States, (2010)

[9] F. Koussa, J. Defrance, P. Jean and P. Blanc-Benon, Acoustic performance of gabions noise barriers: Numerical and experimental approaches, Appl. Acoust., 74(1), 189-197 (2013)

[10]R.J. Wells, Acoustical plenum chambers, Noise Control, 4(4), 9-15 (1958)

[11]J. Kang and M.V. Brocklesby, Feasibility of applying micro-perforated absorbers in acoustic window systems, Appl. Acoust., 66(6), 669-689 (2005)

[12] Y.G. Tong and S.K. Tang, Plenum window insertion loss in the presence of a line source -A scale model study, J. Acoust. Soc. Am., 133(3), 1458-1467 (2013)

[13] Y.G. Tong, S.K. Tang, J. Kang, A. Fung and M.K.L. Yeung, Full scale field study of sound transmission across plenum windows, Appl. Acoust., 89, 244-253 (2015)

[14]BS EN ISO 10140-2, Acoustics - Laboratory measurement of sound insulation of building elements - Part 2: Measurement of airborne sound insulation, British Standard Institution, London, (2009)

[15]J. Kang, An acoustic window system with optimum ventilation and daylighting performance, Noise Vib. Worldw., 37(11), 9-17 (2006)

[16]Department of Transport Welsh Office, Calculation of road traffic noise London London, Her Majesty's Stationery Office, London, United Kingdom, (1988)

[17]BS EN 1793-3, Road traffic noise reducing devices - Test method for determining Part 3: Normalized traffic noise spectrum, British Standard Institution, London, (1998) 